\title{
Decomposition of Urea in the SCR Process: Combination of DFT Calculations and Experimental Results on the Catalytic Hydrolysis of Isocyanic Acid on $\mathrm{TiO}_{2}$ and $\mathrm{Al}_{2} \mathrm{O}_{3}$
}

\author{
Izabela Czekaj · Oliver Kröcher
}

Published online: 10 July 2009

(C) Springer Science+Business Media, LLC 2009

\begin{abstract}
In selective catalytic reduction (SCR) systems for diesel vehicles the injected urea solution decomposes to ammonia and isocyanic acid (HNCO), which reacts with water to another ammonia molecule and carbon dioxide over the SCR catalyst or a special urea decomposition catalyst. The second reaction step, i.e. the catalytic hydrolysis of $\mathrm{HNCO}$ was studied on the anatase $\mathrm{TiO}_{2}(101)$ surface and $\mathrm{Al}_{2} \mathrm{O}_{3}(100)$ surface with ab initio density functional theory (DFT) calculations using a cluster model as well as with in situ diffuse reflectance infrared Fourier transform spectra (DRIFTS) investigations and kinetic experiments. The following mechanistic pathway has been identified to be most feasible: HNCO dissociatively adsorbs on the metal oxide surface as isocyanates, which are attacked by water, thereby forming carbamic acid at the surface. In a further step this intermediate is transformed to a carbamate complex, which leads to $\mathrm{CO}_{2}$ desorption and consequently $\mathrm{NH}_{3}$ formation. The comparison between the sum of the theoretical vibrational spectra of the reaction intermediates with the in situ DRIFT spectra also strongly supports the accuracy of the second reaction pathway. This mechanism holds also for the $\mathrm{HNCO}$ hydrolysis over $\gamma-\mathrm{Al}_{2} \mathrm{O}_{3}$ and the reactivity compared to $\mathrm{TiO}_{2}$ was found to be consistent with the heights of the barriers in the energy diagrams. Based on these promising preliminary results a computational screening has been started in order to predict the most active metal oxides and surfaces for this reaction.
\end{abstract}

I. Czekaj $(\bowtie) \cdot$ O. Kröcher

Department General Energy, Paul Scherrer Institute,

5232 Villigen PSI, Switzerland

e-mail: izabela.czekaj@psi.ch
Keywords Titanium dioxide $\cdot \mathrm{TiO}_{2}(101)$ surface . Aluminium oxide $\cdot \gamma-\mathrm{Al}_{2} \mathrm{O}_{3}(100) \cdot$ DFT $\cdot$ DRIFTS $~$ Cluster model · Isocyanic acid · Carbamic acid . Carbamate group

\section{Introduction}

The selective catalytic reduction (SCR) process with urea is an efficient technology for the reduction of nitrogen oxides emissions of diesel vehicles [1-4]. The reason for the use of urea is its easy thermal decomposition to ammonia, which is the real reducing agent in the SCR reaction. In a typical SCR system urea thermolyses in the hot exhaust gas to ammonia and isocyanic acid (HNCO), which hydrolyzes on the SCR catalyst to ammonia and carbon dioxide [2, 5-18]. The SCR catalyst can be disburdened from this additional reaction by the application of a specialized hydrolysis catalysts upstream of the SCR catalyst $[2,5,6]$. We screened a series of single and mixed metal oxides for this reaction and titania in the anatase modification was found to be a most active [19]. Compared to titania, alumina proved to be much less active and silica showed only low activity for the HNCO hydrolysis. In order to explain the superior properties of titania for this reaction we investigated the mechanism of the HNCO hydrolysis on the $\mathrm{TiO}_{2}$ anatase (101) surface by a combination of DFT calculations and experimental techniques [20,21]. Two reaction pathways could be identified, a first in which water enters the reaction sequence at a late stage and which proceeds via molecular adsorption of HNCO and oxygen vacancy formation [20], and a second in which water is involved right from the beginning and which proceeds by dissociative adsorption of HNCO and carbamic acid formation [21]. The second reaction scheme with an early participation of water is more likely than our 
first reaction scheme since it involves lower energy barriers. Moreover, the measured reaction orders of the HNCO hydrolysis over $\mathrm{TiO}_{2}$ and the measured in situ DRIFT spectra could only be reconciled with the second reaction pathway.

The scope of the present work was to extend our theoretical study on the hydrolysis of $\mathrm{HNCO}$ over titania to other metal oxide catalysts. We chose $\gamma-\mathrm{Al}_{2} \mathrm{O}_{3}$ as second candidate since it was found to be also quite active for the HNCO hydrolysis [19] and since it plays an important role in other $\mathrm{NO}_{x}$ reduction processes as well [22]. Numerous theoretical studies about pure and modified $\gamma-\mathrm{Al}_{2} \mathrm{O}_{3}$ systems were performed previously [23-25] using both periodic and cluster models. Other reasons for our selection of $\gamma-\mathrm{Al}_{2} \mathrm{O}_{3}$ were that it is a single metal oxide and that a similar HNCO hydrolysis mechanism can be assumed on this rather simple material. Although it is reasonable to assume that this relatively simple reaction proceeds via the same mechanism over different metal oxides, this assumption has to be carefully checked for every new material. In our study, the hydrolysis of $\mathrm{HNCO}$ on $\mathrm{Al}_{2} \mathrm{O}_{3}(100)$ was compared with that on $\mathrm{TiO}_{2}(101)$ by modeling the $\mathrm{O}_{\mathrm{s}}-\mathrm{M}_{\mathrm{s}}$ unit of both materials with large molecular clusters using the density functional theory. This comparative study is a first step towards our goal to establish a virtual screening of catalysts for this reaction, which can provide energy barriers, activation energies and activities of different catalysts without the influence of the preparation method. The activity of real catalysts is determined by the share of the different modifications in the bulk and the share of the exposed surfaces as well as by the surface area, pores size distribution and other factors, such as impurities.

\section{Methods}

\subsection{Calculations}

The tetragonal anatase phase of titanium dioxide, $\mathrm{TiO}_{2}$, was chosen for our investigations (see details in [20]). The
$\mathrm{TiO}_{2}$ anatase (101) surface is shown in Fig. 1a, where the different titanium and oxygen sites are highlighted.

The cubic phase [26, 27] of defective alumina spinel, $\mathrm{Al}_{2} \mathrm{O}_{3}$, is described by the space group $\mathrm{Fd}-3 \mathrm{~m}$ with lattice constants $\mathrm{a}=\mathrm{b}=\mathrm{c}=7.911 \AA$. The crystal unit cell of defective alumina spinel contains 56 atoms, where $\mathrm{Al}$ occupies two different types of positions-8a, 16d, and oxygen $32 \mathrm{e}$ sites.

Inside the bulk both $\mathrm{AlO}_{6}$ octahedra and $\mathrm{AlO}_{4}$ tetrahedra are present with $\mathrm{Al}-\mathrm{O}$ distances equal to 1.94 and $1.78 \AA$, respectively. The bulk is built by six- and four-fold coordinated aluminium and three- and four-fold coordinated oxygen. Figure 1c shows the structure of the $\gamma-\mathrm{Al}_{2} \mathrm{O}_{3}(100)$ surface. Two different aluminium sites with four- and fivefold coordinated aluminium, $\mathrm{AlO}_{4}$ and $\mathrm{AlO}_{5}$, as well as two different three-fold coordinated oxygen sites, $\mathrm{O}(3)$ and $\mathrm{O}^{\prime}(3)$, can be distinguished. It is important to note that $\mathrm{Al}(4)$ is always located below the $\mathrm{Al}(5)$ centres and that the rows of $\mathrm{AlO}_{5}$ pyramids are separated from each others by rows of $\mathrm{AlO}_{4}$ tetrahedra.

Two surface planes are predominantly detected in the diffraction patterns of $\gamma-\mathrm{Al}_{2} \mathrm{O}_{3}$, namely the (110) and (100) surfaces. Following some previous studies of alumina by Handzlik et al. [23], the (100) surface was chosen for our studies. Three different distances are observed between the aluminium atoms on the (100) surface of alumina: (i) $3.28 \AA$ between $\mathrm{Al}(4)-\mathrm{Al}(5)$ atoms, (ii) $2.79 \AA$ between $\mathrm{Al}(5)-\mathrm{Al}(5)$ atoms in the $\mathrm{AlO}_{5}$ row and (iii) $5.59 \AA$ between $\mathrm{Al}(4)-\mathrm{Al}(4)$ atoms. The surface exhibits specific holes with a distance of 2.90 and $2.79 \AA$ between the $\mathrm{O}(3)$ atoms. The adsorbates have good access to the electrophilic $\mathrm{M}(5)$ centers, which are, therefore, preferably covered by $\mathrm{HNCO}$ and $\mathrm{H}_{2} \mathrm{O}$.

In our studies the catalyst surfaces were modeled by clusters of different size and geometry, which were saturated by hydrogen atoms with $\mathrm{R}_{\mathrm{OH}}=0.97 \AA$. For modeling of the $\mathrm{TiO}_{2}(101)$ surface, the clusters $\mathrm{Ti}_{2} \mathrm{O}_{9} \mathrm{H}_{10}, \mathrm{Ti}_{8} \mathrm{O}_{28} \mathrm{H}_{24}$, $\mathrm{Ti}_{13} \mathrm{O}_{43} \mathrm{H}_{34}$ and $\mathrm{Ti}_{15} \mathrm{O}_{50} \mathrm{H}_{40}$ were selected [20], among which the $\mathrm{Ti}_{8} \mathrm{O}_{28} \mathrm{H}_{24}$ cluster proved to be best suited for the further reaction studies (Fig. 1b). In case of $\gamma-\mathrm{Al}_{2} \mathrm{O}_{3}$, the
Fig. 1 Characteristic surface sites at a $\mathrm{TiO}_{2}$ anatase (101) and $\mathbf{c} \mathrm{Al}_{2} \mathrm{O}_{3}(100)$ and the corresponding model clusters b $\mathrm{Ti}_{8} \mathrm{O}_{28} \mathrm{H}_{24}$ and $\mathbf{d ~} \mathrm{Al}_{11} \mathrm{O}_{30} \mathrm{H}_{27}$

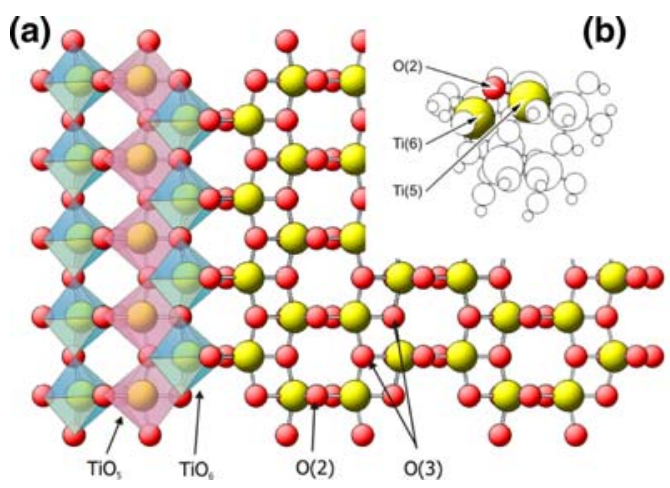

(c)

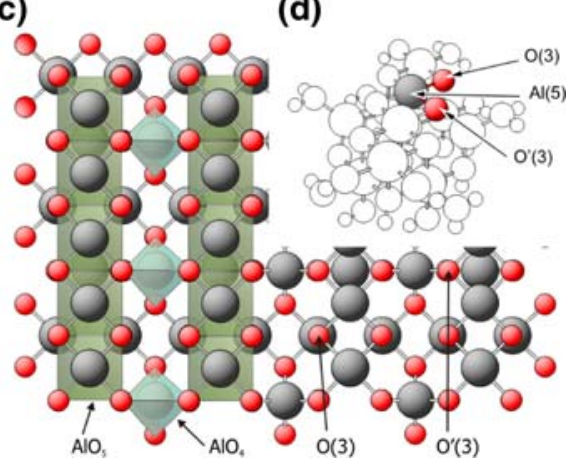


clusters $\mathrm{Al}_{11} \mathrm{O}_{30} \mathrm{H}_{27}, \mathrm{Al}_{15} \mathrm{O}_{40} \mathrm{H}_{35}$ and $\mathrm{Al}_{25} \mathrm{O}_{58} \mathrm{H}_{41}$ were checked, from which $\mathrm{Al}_{11} \mathrm{O}_{30} \mathrm{H}_{27}$ was finally selected for this study (Fig. 1d).

The electronic structure of clusters and of all reaction intermediates was calculated by ab initio density functional theory (DFT) methods (StoBe code [28]) using the generalized gradient corrected functional (RPBE) [29, 30] and linear combinations of atomic orbitals [31, 32]. A double zeta valence polarization (DZVP) type was used for the orbital basis sets of $\mathrm{Ti}(63321 / 531 / 41), \mathrm{Al}$ (6321/521/1), O, $\mathrm{C}, \mathrm{N}(621 / 41 / 1)$, and $\mathrm{H}(41)$. Auxiliary basis sets, such as $(5,5 ; 5,5)$ for $\mathrm{Ti},(5,4 ; 5,4)$ for $\mathrm{Al},(4,3: 4,3)$ for $\mathrm{O}, \mathrm{C}, \mathrm{N}$, and (41) for $\mathrm{H}$, were applied to fit the electron density and the exchange-correlation potential. A detailed analysis of the electronic structure of the clusters was carried out using Mulliken populations [33] and Mayer bond order indices $[34,35]$. In the calculations for all reaction steps, the low spin states were found to be energetically favorable.

The adsorption energies of the adsorbates on the $\mathrm{M}_{\mathrm{x}} \mathrm{O}_{\mathrm{y}} \mathrm{H}_{\mathrm{z}}$ cluster were calculated as follows:

$$
\begin{aligned}
\mathrm{E}_{\mathrm{ad}}(\text { adsorbate } / \text { catalyst })= & \mathrm{E}_{\text {tot }}\left(\text { adsorbate } / \mathrm{M}_{\mathrm{x}} \mathrm{O}_{\mathrm{y}} \mathrm{H}_{\mathrm{z}}\right) \\
& -\mathrm{E}_{\text {tot }}\left(\mathrm{M}_{\mathrm{x}} \mathrm{O}_{\mathrm{y}} \mathrm{H}_{\mathrm{z}}\right) \\
& -\mathrm{E}_{\text {tot }}(\text { adsorbate }),
\end{aligned}
$$

where $E_{\text {tot }}$ (adsorbate $/ \mathrm{M}_{\mathrm{x}} \mathrm{O}_{\mathrm{y}} \mathrm{H}_{\mathrm{z}}$ ) is the total energy of the adsorbate/catalyst surface complex, $\mathrm{E}_{\text {tot }}\left(\mathrm{M}_{\mathrm{x}} \mathrm{O}_{\mathrm{y}} \mathrm{H}_{\mathrm{z}}\right)$ and $\mathrm{E}_{\text {tot }}$ (adsorbate) are the total energies of pure $\mathrm{M}_{\mathrm{x}} \mathrm{O}_{\mathrm{y}} \mathrm{H}_{\mathrm{z}}$ and the adsorbate, respectively.

The calculations of the vibrational frequencies were performed with harmonic approximations as well as an anharmonicity fit in the Morse potential function, as implemented into StoBe code [36]. Theoretical vibrational spectra were obtained by convolution of the vibrational spectra of the individual adsorbates, applying Gaussian line-shapes. The frequencies are reported as obtained from the calculations, without scaling.

\subsection{Experiments}

Powdered $\mathrm{TiO}_{2}$ in the anatase modification was used in the experimental investigations $\left(S_{\mathrm{BET}}=57 \mathrm{~m}^{2} / \mathrm{g}\right)$. Isocyanic acid was produced by thermal decomposition of cyanuric acid and subsequently mixed with the feed gas, as described in [1].

A Thermo Nicolet Nexus 860 FT-IR spectrometer was used to for the in situ measurement of diffuse reflectance infrared Fourier transform spectra (DRIFTS). The catalyst sample was purged in situ for $1 \mathrm{~h}$ at $450{ }^{\circ} \mathrm{C}$ with a flow of $\mathrm{N}_{2}$ gas. The studies of $\mathrm{HNCO}$ adsorption were performed at various temperatures up to $450{ }^{\circ} \mathrm{C}$. At each temperature the catalyst was first been treated with $\approx 70 \mathrm{ppm}$ of $\mathrm{HNCO}$ in $\mathrm{N}_{2}$ for $15 \mathrm{~min}$ and then exposed to a $\mathrm{N}_{2}$ flow for $15 \mathrm{~min}$ in order to remove physisorbed adsorbates from the surface.
Finally, water pulses were added through a capillary to start the hydrolysis reaction.

\section{Results and Discussion}

The calculations revealed that dissociative as well as molecular adsorption of HNCO is possible and energetically feasible on both the $\mathrm{TiO}_{2}(101)$ [19] and the $\mathrm{Al}_{2} \mathrm{O}_{3}(100)$ surface $[37,38]$. Figure 2 shows the geometric and electronic structures of $\mathrm{HNCO}$ and the interacting sites of $\mathrm{TiO}_{2}(101)$ and $\mathrm{Al}_{2} \mathrm{O}_{3}(100)$, represented by the $\mathrm{Ti}_{8} \mathrm{O}_{28} \mathrm{H}_{24}$ (see Fig. 1b) and the $\mathrm{Al}_{11} \mathrm{O}_{30} \mathrm{H}_{27}$ cluster (see Fig. 1d). Information about adsorption energy, atomic charges (Mulliken analysis), distances $(\AA)$ and bond orders (Mayer bond analysis) are also included in Table 1 .

For investigation of the reaction mechanism of the $\mathrm{HNCO}$ hydrolysis the co-adsorption of $\mathrm{HNCO}$ and $\mathrm{H}_{2} \mathrm{O}$ at the catalyst surface had to be considered, which comprises the competitive adsorption of water and $\mathrm{HNCO}$ and the interaction of water from the gas phase with $\mathrm{HNCO}$ adsorbates. This requires the presence of free neighbored five-fold coordinated metal sites.

Figure 3 shows a comparison of the energy levels for the intermediates observed during hydrolysis of HNCO. Adsorption of $\mathrm{HNCO}$ is actually possible in the presence of water, because the dissociative adsorption of HNCO is energetically competitive to the dissociative adsorption of water on the $\mathrm{TiO}_{2}$ and $\mathrm{Al}_{2} \mathrm{O}_{3}$ surface. The $-\mathrm{NCO}$ group is stabilized at a $\mathrm{M}(5)$ center with an adsorption energy of
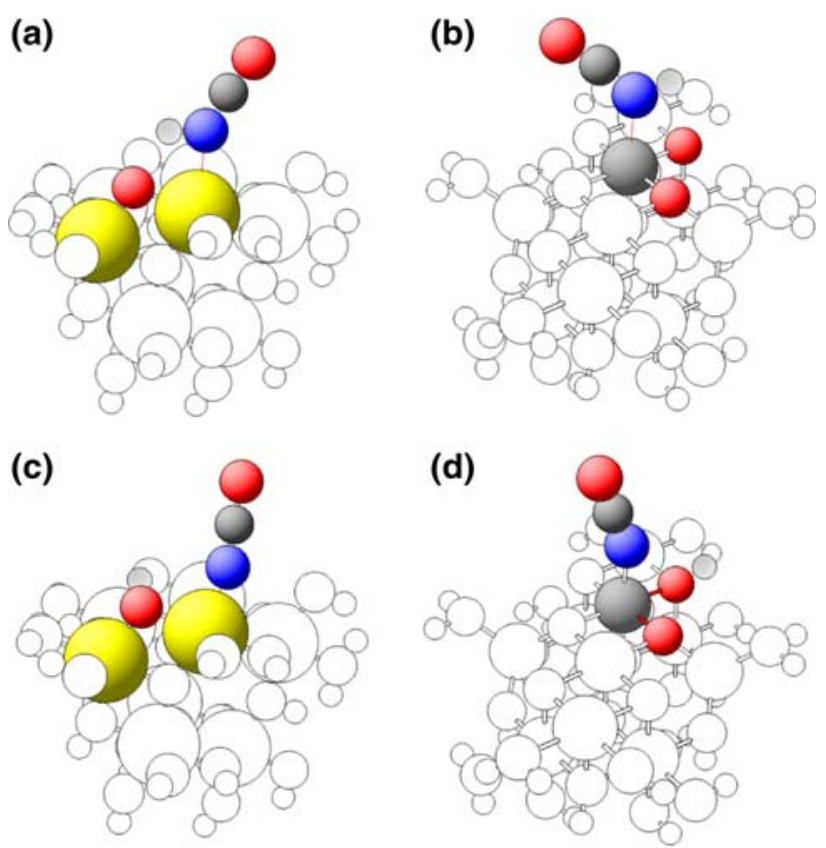

Fig. 2 a, b Molecular and $\mathbf{c}, \mathbf{d}$ dissociative $\mathrm{HNCO}$ adsorption at a, c $\mathrm{TiO}_{2}(101)$ and $\mathbf{b}, \mathbf{d} \gamma-\mathrm{Al}_{2} \mathrm{O}_{3}(100)$ 
Table 1 The HNCO adsorption at $\mathrm{TiO}_{2}(101)$ and $\gamma-\mathrm{Al}_{2} \mathrm{O}_{3}(100)$

$$
\mathrm{TiO}_{2}
$$$$
\mathrm{Al}_{2} \mathrm{O}_{3}
$$

\begin{tabular}{|c|c|c|c|c|}
\hline & \multicolumn{2}{|l|}{$\mathrm{TiO}_{2}$} & \multicolumn{2}{|l|}{$\mathrm{Al}_{2} \mathrm{O}_{3}$} \\
\hline \multicolumn{5}{|l|}{ (a) Molecular } \\
\hline $\mathrm{E}_{\mathrm{B}}(\mathrm{HNCO})(\mathrm{eV})$ & \multicolumn{2}{|l|}{-0.40} & \multicolumn{2}{|l|}{-0.72} \\
\hline $\mathrm{E}_{\mathrm{B}}\left(\mathrm{H}_{2} \mathrm{O}\right)(\mathrm{eV})$ & \multicolumn{2}{|l|}{-1.19} & \multicolumn{2}{|l|}{-1.52} \\
\hline N-M b.o. (b.d. $[\AA]$ ) & \multicolumn{2}{|l|}{$0.20(2.43)$} & \multicolumn{2}{|l|}{$0.18(2.26)$} \\
\hline N-C b.o. (b.d. $[\AA]$ ) & \multicolumn{2}{|l|}{$1.95(1.24)$} & \multicolumn{2}{|l|}{$1.84(1.25)$} \\
\hline \multicolumn{5}{|l|}{ (b) Dissociative } \\
\hline $\mathrm{E}_{\mathrm{B}}(\mathrm{HNCO})(\mathrm{eV})$ & \multicolumn{2}{|l|}{-0.91} & \multicolumn{2}{|l|}{-1.11} \\
\hline $\mathrm{E}_{\mathrm{B}}\left(\mathrm{H}_{2} \mathrm{O}\right)(\mathrm{eV})$ & \multicolumn{2}{|l|}{-0.84} & \multicolumn{2}{|l|}{-1.06} \\
\hline N-M b.o. (b.d. $[\AA]$ ) & \multicolumn{2}{|l|}{$0.59(1.99)$} & \multicolumn{2}{|l|}{$0.68(1.94)$} \\
\hline N-C b.o. (b.d. $[\AA]$ ) & \multicolumn{2}{|l|}{$2.23(1.21)$} & \multicolumn{2}{|l|}{$2.16(1.21)$} \\
\hline \multicolumn{5}{|c|}{ (c) Calculated vibrational frequencies $\left(\mathrm{cm}^{-1}\right)$ of individual surface intermediates } \\
\hline & Sym. & Asym. & Sym. & Asym. \\
\hline \multicolumn{5}{|l|}{$v(\mathrm{NCO})$} \\
\hline HNCO & 1279 & 2266 & 1263 & 2264 \\
\hline $\mathrm{NCO}_{\mathrm{aq}}$ & 1351 & 2194 & 1342 & 2274 \\
\hline $\mathrm{NCO}$ & 1345 & 2181 & 1364 & 2293 \\
\hline \multicolumn{5}{|l|}{$v(\mathrm{~N}-\mathrm{H} / \mathrm{H}-\mathrm{N}-\mathrm{H})$} \\
\hline $\mathrm{NHCOOH}$ & 3462 & - & 3280 & - \\
\hline $\mathrm{NH}_{2} \mathrm{CO}_{2}$ & 3346 & 3482 & 3364 & 3488 \\
\hline $\mathrm{NH}_{2 \mathrm{aq}}$ & $2905 / 3349$ & 3466 & $3406 / 3425$ & 3533 \\
\hline $\mathrm{NH}_{3 \mathrm{aq}}$ & $2955 / 3381$ & 3492 & $3068 / 3394$ & 3484 \\
\hline
\end{tabular}

(c) Calculated vibrational frequencies $\left(\mathrm{cm}^{-1}\right)$ of individual surface intermediates

\begin{tabular}{|c|c|c|c|c|}
\hline & \multicolumn{2}{|l|}{$\mathrm{TiO}_{2}$} & \multicolumn{2}{|l|}{$\mathrm{Al}_{2} \mathrm{O}_{3}$} \\
\hline \multicolumn{5}{|l|}{ (a) Molecular } \\
\hline $\mathrm{E}_{\mathrm{B}}(\mathrm{HNCO})(\mathrm{eV})$ & \multicolumn{2}{|l|}{-0.40} & \multicolumn{2}{|l|}{-0.72} \\
\hline $\mathrm{E}_{\mathrm{B}}\left(\mathrm{H}_{2} \mathrm{O}\right)(\mathrm{eV})$ & \multicolumn{2}{|l|}{-1.19} & \multicolumn{2}{|l|}{-1.52} \\
\hline N-M b.o. (b.d. $[\AA]])$ & \multicolumn{2}{|l|}{$0.20(2.43)$} & \multicolumn{2}{|l|}{$0.18(2.26)$} \\
\hline N-C b.o. (b.d. $[\AA]$ ) & \multicolumn{2}{|l|}{$1.95(1.24)$} & \multicolumn{2}{|l|}{$1.84(1.25)$} \\
\hline \multicolumn{5}{|l|}{ (b) Dissociative } \\
\hline $\mathrm{E}_{\mathrm{B}}(\mathrm{HNCO})(\mathrm{eV})$ & \multicolumn{2}{|l|}{-0.91} & \multicolumn{2}{|l|}{-1.11} \\
\hline $\mathrm{E}_{\mathrm{B}}\left(\mathrm{H}_{2} \mathrm{O}\right)(\mathrm{eV})$ & \multicolumn{2}{|l|}{-0.84} & \multicolumn{2}{|l|}{-1.06} \\
\hline N-M b.o. (b.d. $[\AA]$ ) & \multicolumn{2}{|l|}{$0.59(1.99)$} & \multicolumn{2}{|l|}{$0.68(1.94)$} \\
\hline N-C b.o. (b.d. $[\AA]$ ) & \multicolumn{2}{|l|}{$2.23(1.21)$} & \multicolumn{2}{|l|}{$2.16(1.21)$} \\
\hline \multicolumn{5}{|c|}{ (c) Calculated vibrational frequencies $\left(\mathrm{cm}^{-1}\right)$ of individual surface intermediates } \\
\hline & Sym. & Asym. & Sym. & Asym. \\
\hline \multicolumn{5}{|l|}{$v(\mathrm{NCO})$} \\
\hline $\mathrm{HNCO}$ & 1279 & 2266 & 1263 & 2264 \\
\hline $\mathrm{NCO}_{\mathrm{aq}}$ & 1351 & 2194 & 1342 & 2274 \\
\hline $\mathrm{NCO}$ & 1345 & 2181 & 1364 & 2293 \\
\hline \multicolumn{5}{|l|}{$v(\mathrm{~N}-\mathrm{H} / \mathrm{H}-\mathrm{N}-\mathrm{H})$} \\
\hline $\mathrm{NHCOOH}$ & 3462 & - & 3280 & - \\
\hline $\mathrm{NH}_{2} \mathrm{CO}_{2}$ & 3346 & 3482 & 3364 & 3488 \\
\hline $\mathrm{NH}_{2 \mathrm{aq}}$ & $2905 / 3349$ & 3466 & $3406 / 3425$ & 3533 \\
\hline $\mathrm{NH}_{3 \mathrm{aq}}$ & $2955 / 3381$ & 3492 & $3068 / 3394$ & 3484 \\
\hline
\end{tabular}

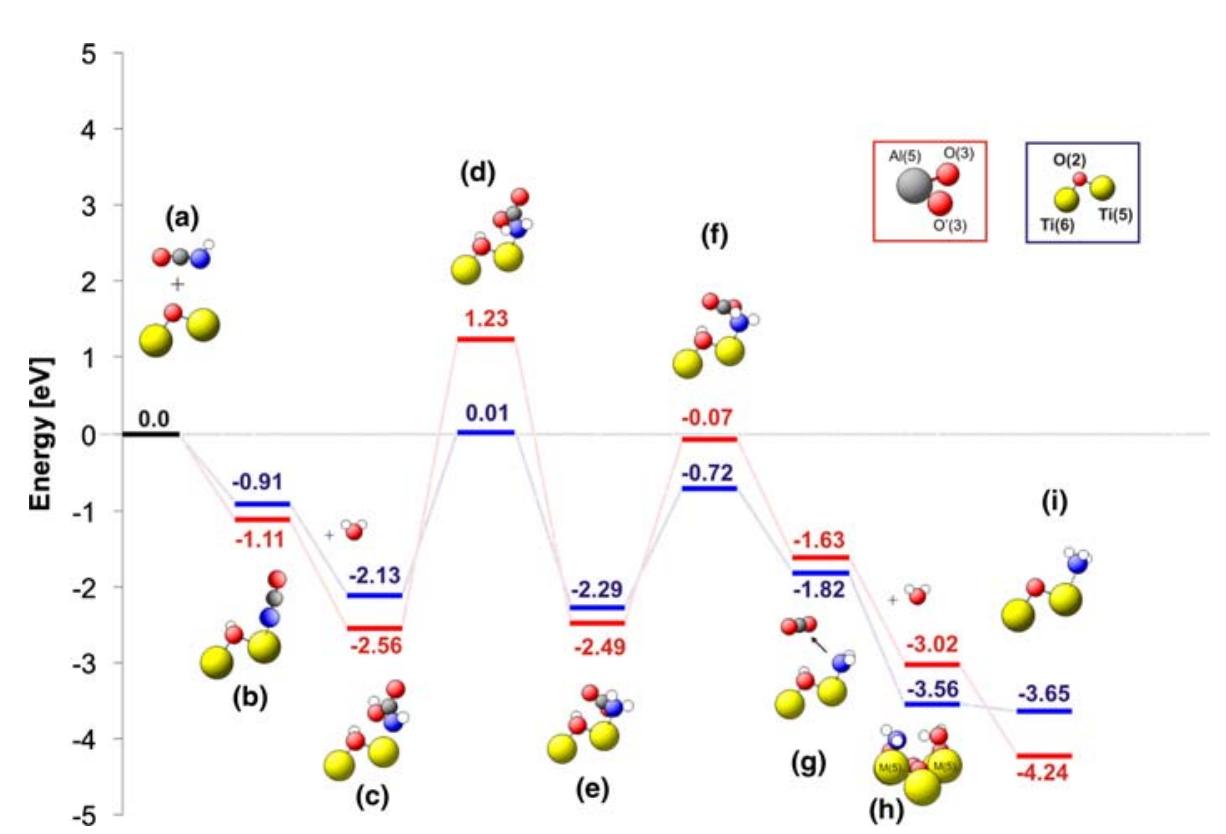

Fig. 3 The energy diagram for the hydrolysis of $\mathrm{HNCO}$ on $\mathrm{TiO}_{2}(101)$ (blue levels) and $\gamma-\mathrm{Al}_{2} \mathrm{O}_{3}(100)$ (red levels): a Cluster + HNCO reference level. b Dissociative adsorption of $\mathrm{HNCO}$ on the catalyst. c Water attack on the NCO group at the $\mathrm{M}(5)$ site and formation of surface carbamic acid $(\mathrm{NHCOOH})$. d Transfer of the carboxyl $\mathrm{H}$ to the $\mathrm{NH}$ group. e Formation of adsorbed carbamate $\left(\mathrm{NH}_{2} \mathrm{CO}_{2}\right)$ at the $\mathrm{M}(5)$ site. $\mathbf{f ~} \mathrm{CO}_{2}$ separation from the $\mathrm{NH}_{2}$ surface group. $\mathbf{g ~ C O}$ desorption and stabilization of the $\mathrm{NH}_{2}$ group at $\mathrm{M}(5)$. $\mathbf{h}$ Migration of the $\mathrm{H}$ from adsorbed water to $\mathrm{NH}_{2}$. $\mathrm{i} \mathrm{NH}$ at the $\mathrm{M}(5)$ site
-0.91 and $-1.11 \mathrm{eV}$ (see Fig. 3b) for $\mathrm{TiO}_{2}$ and $\mathrm{Al}_{2} \mathrm{O}_{3}$, respectively, whereas water adsorbs dissociatively with an adsorption energy of $\mathrm{E}_{\mathrm{ad}}=-0.84$ and $-1.06 \mathrm{eV}$ (see Table 1). Although molecular adsorption of water should be energetically even more favored $\left(\mathrm{E}_{\mathrm{ad}}=-1.19 /-1.52 \mathrm{eV}\right)$, dissociative adsorption of water is observed over the whole temperature range and even at very low temperatures $\left(50{ }^{\circ} \mathrm{C}\right)[19]$.

The -NCO groups at the catalyst surface are attacked by a water molecule from the gas phase and a carbamic acid complex is immediately formed $(-\mathrm{NHCOOH})$. As shown in Fig. 3c, the carbamic acid is bound to the M(5) atoms with 
an adsorption energy of $-2.13 \mathrm{eV}\left(\mathrm{TiO}_{2}\right)$ and $-2.56 \mathrm{eV}$ $\left(\mathrm{Al}_{2} \mathrm{O}_{3}\right)$. By a change of the conformation of the carbamic acid, in which the hydrogen atom at the oxygen is internally transferred to the nitrogen, a carbamate complex $\left(-\mathrm{NH}_{2} \mathrm{CO}_{2}\right)$ can be formed at the surface (Fig. 3e). This process requires a high energy of about $2.14 \mathrm{eV}$ for $\mathrm{TiO}_{2}$ and $3.79 \mathrm{eV}$ for $\mathrm{Al}_{2} \mathrm{O}_{3}$ (Fig. 3d) with respect to the carbamic acid level (Fig. 3c). As a matter of fact, the high energy needed for the internal hydrogen transfer from the carboxylate group in $-\mathrm{NHCOOH}$ to the nitrogen in $\mathrm{H}_{2} \mathrm{NCOO}$ could be overcome in the real system by dehydrogenation of carboxylate group to another molecule (e.g. water) and hydrogenation of the $-\mathrm{NH}$ group from an external hydrogen source. The important fact is that the formation of the carbamate complex from carbamic acid (Fig. 4c-e) is exothermic for $\mathrm{TiO}_{2}(-0.16 \mathrm{eV})$ and slightly endothermic for $\mathrm{Al}_{2} \mathrm{O}_{3}(0.07 \mathrm{eV})$. The carbamate complex decarboxylates (Fig. 3g) and the $\mathrm{NH}_{2}$ group remains at the $\mathrm{M}(5)$ atom. The hydrogen missing for the formation of ammonia can be obtained from a water molecule adsorbed at a neighboring $\mathrm{M}(5)$ atom. The hydrogen transfer from a second water molecule is facilitated by the very low energy level of the system after the adsorption of water $(-3.56 \mathrm{eV}$ for $\mathrm{TiO}_{2}$ and $-3.02 \mathrm{eV}$ for $\mathrm{Al}_{2} \mathrm{O}_{3}$; Fig. 3h). The $\mathrm{NH}_{3}$, formed by the reaction of $\mathrm{NH}_{2}$ groups with adsorbed water molecules, is finally released from the catalyst surface, which enriches the catalyst surface with $\mathrm{OH}$ groups. This is in agreement with the in situ DRIFTS experiments described below, since strong $\mathrm{OH} /$ water vibrations are always visible after reaction.

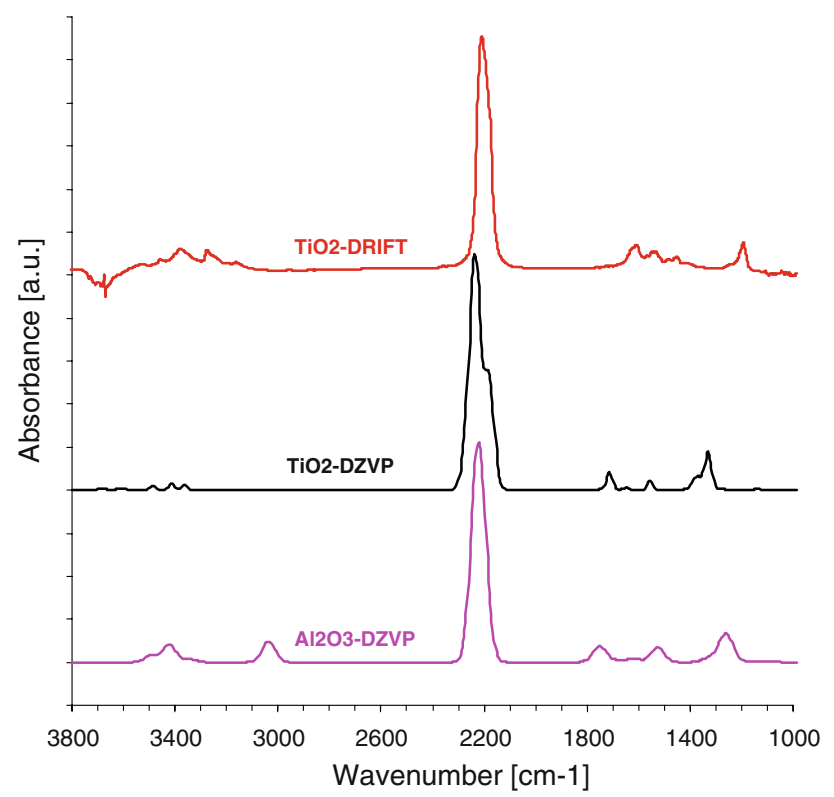

Fig. 4 Theoretical vibrational IR spectra and experimental DRIFT spectra of $\mathrm{TiO}_{2}$ after $\mathrm{HNCO}$ adsorption $(70 \mathrm{ppm})$ at $150{ }^{\circ} \mathrm{C}$ for $15 \mathrm{~min}$ followed by purging with nitrogen for $15 \mathrm{~min}$ as well as theoretical vibrational IR spectra of $\mathrm{Al}_{2} \mathrm{O}_{3}$ after $\mathrm{HNCO}$ adsorption
The comparison between the theoretical vibrational spectra of the reaction intermediates of the HNCO adsorption on $\mathrm{TiO}_{2}$ and $\mathrm{Al}_{2} \mathrm{O}_{3}$ with the in situ DRIFT spectrum for $\mathrm{TiO}_{2}$ is shown at Fig. 4. The theoretical spectra were obtained by summation of the spectra of the individual adsorbates such as ammonia, carbamic acid and HNCO as well as amino, carbamate, and isocyanate groups, each influenced by an aqueous environment in form of $\mathrm{H}_{2} \mathrm{O}$ or $\mathrm{OH}$ groups.

Exposure of the catalyst to $\mathrm{HNCO}$ at $150{ }^{\circ} \mathrm{C}$ resulted in the evolution of a strong band at $2209 \mathrm{~cm}^{-1}$ together with less intense bands in the range 3524-3163 and 1619$1190 \mathrm{~cm}^{-1}$ (see upper spectrum in Fig. 4). Some of vibrations calculated theoretically are listed in Table 1c. The strong band at $2209 \mathrm{~cm}^{-1}$ is assigned to the asymmetric stretching vibrations of -NCO groups adsorbed at the surface. From our theoretical studies we found that the main contributions to these vibrations come from dissociatively adsorbed $\mathrm{HNCO}$ stabilized by $\mathrm{M}(5)$ centers evoking the vibration at $2234 \mathrm{~cm}^{-1}$ in the neighborhood of strong $\mathrm{OH}$ groups and the vibration at $2181 \mathrm{~cm}^{-1}$ in the absence of $\mathrm{OH}$ groups. However, small amounts of weakly adsorbed HNCO in molecular form can be found at $2266 \mathrm{~cm}^{-1}$, which is very close to the vibration of gaseous HNCO. Our theoretically predicted vibrations on $\mathrm{TiO}_{2}$ are consistent with results of Hauck et al. [38], where this band has components at 2189,2230 and $2255 \mathrm{~cm}^{-1}$. In the case of the $\mathrm{Al}_{2} \mathrm{O}_{3}$ catalyst the theoretically predicted vibrations of the $-\mathrm{NCO}$ groups are at $2274 \mathrm{~cm}^{-1}$ in case of dissociative adsorption and at $2264 \mathrm{~cm}^{-1}$ in case of molecularly adsorbed HNCO. These vibrations are also in good agreement with experimental data presented recently by Ozensoy et al. [22], who recorded TD-FTIR spectra at $120^{\circ} \mathrm{C}$ and who found bands at 2143 and $2254 \mathrm{~cm}^{-1}$. The calculated vibrations of $\mathrm{NCO}_{\mathrm{aq}}$ and $\mathrm{HNCO}$ are very close to each other, which suggests that on $\mathrm{Al}_{2} \mathrm{O}_{3}$ more $\mathrm{HNCO}$ can be found in molecular form. This is in good agreement with the higher adsorption energy of molecular $\mathrm{HNCO}$ on $\mathrm{Al}_{2} \mathrm{O}_{3}$ $(-0.72 \mathrm{eV})$ compared to $\mathrm{TiO}_{2}(-0.40 \mathrm{eV})$ (Table 1a).

The theoretical bands below $1800 \mathrm{~cm}^{-1}$ and above $3000 \mathrm{~cm}^{-1}$ in Fig. 4 have a similar shape as in the experimental $\mathrm{TiO}_{2}$ spectrum, but they are slightly shifted to higher frequencies. The lower-frequency bands (1200-1800 $\left.\mathrm{cm}^{-1}\right)$ in the calculated spectrum in Fig. 4 correspond to the bending vibrations of $\mathrm{NH}_{2}$ or $\mathrm{NH}_{3}$ as well as $\mathrm{NH}_{2} \mathrm{CO}_{2}$ and $\mathrm{NHCOOH}$ and the symmetric stretching vibrations of $\mathrm{NCO}$ influenced by water. The high-frequency bands (3000$3500 \mathrm{~cm}^{-1}$ ) are the sum of the $\mathrm{N}-\mathrm{H}$ stretching vibrations of the individual adsorbates (see Table 1c) influenced by water.

The intermediate complexes, such as $-\mathrm{NCO}$ or carbamic acid, have stronger stabilisation energies at the $\mathrm{Al}_{2} \mathrm{O}_{3}$ surface, which simply means that it will be more difficult to convert them into the following surface complexes. This 


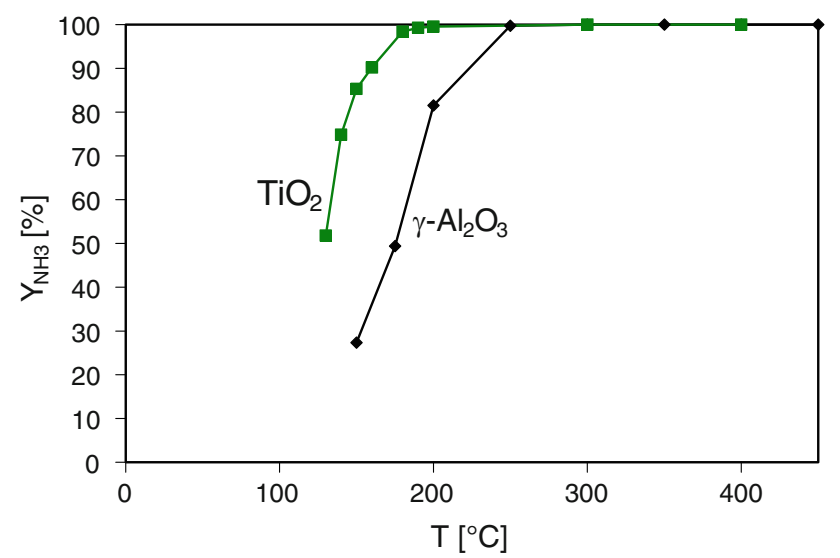

Fig. 5 Catalytic activity of a $\mathrm{TiO}_{2}$ (anatase) and $\mathbf{b} \gamma-\mathrm{Al}_{2} \mathrm{O}_{3}$ in the HNCO hydrolysis. $\mathrm{W}_{\text {cat. }}=150 \mathrm{mg}$, gas flow rate $=200 \mathrm{~L}_{\mathrm{N}} / \mathrm{h}$, inlet flow composition $=1000 \mathrm{ppm} \mathrm{HNCO}, 5 \% \mathrm{H}_{2} \mathrm{O}, 10 \% \mathrm{O}_{2}$ and $\mathrm{N}_{2}$ balance

result is in agreement with our experimental result that $\mathrm{Al}_{2} \mathrm{O}_{3}$ has a lower activity than $\mathrm{TiO}_{2}$ for the $\mathrm{HNCO}$ hydrolysis (Fig. 5).

\section{Conclusions}

DFT calculations show that the hydrolysis of $\mathrm{HNCO}$ is possible over both $\mathrm{TiO}_{2}$ and $\mathrm{Al}_{2} \mathrm{O}_{3}$ catalysts and proceeds along similar reaction paths. The course of the reaction can be summarized as follows: water attacks the - NCO group and a carbamic acid complex is formed at the surface in an exothermic reaction without an energy barrier. Then, the carbamic acid is transformed into a carbamate complex, which leads to $\mathrm{CO}_{2}$ desorption and the formation of an $\mathrm{NH}_{2}$ group. In the last step of the hydrolysis reaction, $\mathrm{NH}_{3}$ is formed via hydrogen transfer from an $\mathrm{OH}$ group or from molecularly adsorbed water, the latter being energetically favored. It is important to note that the reaction occurs with a lower energy barriers on the $\mathrm{TiO}_{2}(101)$ than on the $\mathrm{Al}_{2} \mathrm{O}_{3}(100)$ surface. Two conditions for HNCO hydrolysis catalysts are the existence of free $\mathrm{M}(5)$ sites and surface reactivity with water. There is a large population of $\mathrm{M}(5)$ sites at the surface of both catalysts, but they differently interact with water and $\mathrm{HNCO}$, i.e. reaction intermediates, such as water, NCO species, carbamic intermediates and $\mathrm{NH}_{x}$ species are bound with unequal strength. The intermediates are much stronger bound to the alumina surface which leads to higher reaction barriers and makes alumina unfavorable for HNCO hydrolysis, in accordance with the experimentally found order of activities.

Acknowledgement The calculations were done partially using the unix farm and the linux farm at the Paul Scherrer Institute as well as at the Swiss National Supercomputing Centre.

\section{References}

1. Piazzesi G, Kröcher O, Elsener M, Wokaun A (2006) Appl Catal B 65:55

2. Kleemann M, Elsener M, Koebel M, Wokaun A (2000) Ind Eng Chem Res 39:4120

3. Belson DJ, Strachan AN (1982) Chem Soc Rev 11:41

4. Koebel M, Elsener M, Marti T (1996) Combust Sci Technol 121:85

5. Busca G, Lietti L, Ramis G, Berti F (1998) Appl Catal B 18:1

6. Piazzesi G, Nicosia D, Devadas M, Kröcher O, Elsener M, Wokaun A (2007) Catal Lett 115:33

7. Beltran A, Sambrano JR, Calatayud M, Sensato FR, Andres J (2001) Surf Sci 490:116

8. Hadjiivanov K, Klissurski DG (1996) Chem Soc Rev 25:61

9. Tsyganenko AA, Filimonov VN (1972) Spectrosc Lett 5:477

10. Ramis G, Busca G, Lorenzelli V, Forzatti P (1990) Appl Catal 64:243

11. Ramis G, Busca G, Lorenzelli V (1987) J Chem Soc Faraday Trans I 83:1591

12. Fernandez A, Leyrer J, Gonzales-Elipe AR, Munuera G, Knozinger H (1988) J Catal 112:489

13. Busca G, Saussey H, Saur O, Lavalley J, Lorenzelli V (1995) Appl Catal 14:245

14. Bredow T, Jug K (1995) Surf Sci 327:398

15. Solymosi F, Rasko J (1980) J Catal 65:235

16. Solymosi F, Bansagi T (1979) J Phys Chem 83:552

17. Branda MM, Belelli PG, Ferullo RM, Castellani NJ (2003) Catal Today $85: 153$

18. Gao H, He H (2005) Spectrochim Acta A 61:1233

19. Piazzesi G (2006) The catalytic hydrolysis of isocyanic acid (HNCO) in the urea-SCR process, PhD thesis, Diss. ETH No. 16693, Zurich

20. Czekaj I, Piazzesi G, Kröcher O, Wokaun A (2006) Surf Sci 600:5158

21. Czekaj I, Kröcher O, Piazzesi G (2008) J Mol Catal A 280:68-80

22. Ozensoy E, Herling D, Szanyi J (2008) Catal Today 136:46

23. Handzlik J, Ogonowski J, Tokarz-Sobieraj R (2005) Catal Today 101:163-173

24. Digne M, Sautet P, Raybaud P, Euzen P, Toulhoat H (2004) J Catal 226:54-68

25. Ionescu A, Allouche A, Aycard JP, Rajzmann M, Hutschka F (2002) J Phys Chem B 106:9359-9366

26. Zhou R-S, Snyder RL (1991) Acta Crystallogr B 47:617-630

27. Verwey EJW (1935) Z Kristallographica 91:317-320

28. The program package StoBe is a modified version of the DFTLCGTO program package DeMon, originally developed by A. St.-Amant and D. Salahub (University of Montreal), with extensions by Pettersson LGM and Hermann K

29. Perdew JP, Burke K, Ernzerhof M (1996) Phys Rev Lett 77:3865

30. Hammer B, Hansen LB, Norskov JK (1999) Phys Rev B 59:7413

31. Labanowski JK, Anzelm JW (eds) (1991) Density functional methods in chemistry. Springer, New York

32. Godbout N, Salahub DR, Andzelm J, Wimmer E (1992) Can J Phys 70:560

33. Mulliken RS (1955) J Chem Phys 23: 1833, 1841, 2388, 2343

34. Mayer I (1983) Chem Phys Lett 97:270

35. Mayer I (1987) J Mol Struct Theochem 149:81

36. Friedrich C (2004) Geometrische, elektronische und vibronische Eigenschaften der reinen und defektbehafteten $\mathrm{V}_{2} \mathrm{O}_{5}(010)$-Oberfläche und deren Wechselwirkung mit Adsorbaten: Theoretische Untersuchungen, FU Berlin

37. Cant NW, Chambers DC, Liu IOY (2003) Appl Catal B 46:551

38. Hauck P, Jentys A, Lercher JA (2007) Catal Today 127:165-175 